José María Felipe Mendoza

Universidad Nacional de Cuyo / CONICET

josefelipemendoza@hotmail.com

\title{
División y clasificación de las ciencias según el comentario de Tomás de Aquino al De Trinitate boeciano
}

\author{
On the division and classification of Science. A \\ reading of Aquinas' commentary of the \\ "De Trinitate"
}

Resumen: El presente artículo se ciñe exclusivamente al texto tomístico De Trinitate por reunir de modo sintético el esfuerzo del mismo Tomás por encauzar racionalmente, y no vía autoridad, la sagrada doctrina de la Trinidad. En ello conviene se destaquen dos rasgos: por un lado, el período juvenil de este comentario $y$, por el otro, su finalidad. Esto es, las páginas de dicho texto no son propiamente una glosa de la letra de Severino Beocio, sino la oportunidad de Tomás de hallar "una solución correcta" a una serie de problemas epistémicos suscitados en torno a la teología en general. En consecuencia, y en el marco de la presente cuestión, se atenderá a la letra de este fraile en lo concerniente a su visión clasificatoria de las ciencias, al margen de que la misma tarea la repite efectivamente el mismo dominico años más tarde, aunque de modo diferente, al comentar los tratados aristotélicos.

Palabras clave: Tomás de Aquino, Boecio, ciencia, filosofía.

\begin{abstract}
This article is exclusively limited to the thomistic De Trinitate text to synthetically gather Thomas' own effort to channel the Sacred Doctrine of the Trinity by the ration and not by the authority. For this, two features should be highlighted: on one hand, the juvenile period of this review, and on the other, its purpose. Thus, the pages of the text are not properly a gloss on Boethius Severinus, but Thomas' opportunity to find "a correct solution" to a number of epistemological problems raised by theology in general. Consequently, in this context, this friar's text will be addressed regarding his vision on the classification of sciences; even if the same Dominican repeated the same task years later, although in a different way, commenting on the Aristotelian treatises.
\end{abstract}

Keywords: Thomas Aquinas, Boethius, science, philosophy. 
Se vuelve oportuno considerar diferenciada y aisladamente el texto De Trinitate de Tomás de Aquino, atendiendo a dos hechos fuertemente significativos en comparación con su glosa de los tratados aristotélicos. Por un lado, el notorio cambio de lenguaje; ${ }^{1}$ por el otro, la justificación de la división de las ciencias sobre la base de la abstracción. ${ }^{2}$ Esto es, si en el comentario al De Trinitate, $^{3}$ y a juicio de ciertos comentadores actuales como Lértora

1 Cfr. Tomás de Aquino: Exposición del De Trinitate de Boecio. Introducción, traducción y notas de A. García Marques y J. A. Fernandez, Eunsa, Pamplona, 1986, p. 24: "El argumento basado en el cambio de terminología tomista respecto al innatismo de los principios. [...] Pero después del De Ver. q. 10, a.6 no vuelve a presentarse esa terminología, e incluso cabe hablar de un cambio de carácter doctrinal." Por lo demás, las traducciones figuradas en el presente artículo son personales, a juicio de que la traducción de García Marques si bien es sustancialmente fiel en numerosos aspectos al latín tomasiano, es también confusa en algunos pasajes de dicha obra. Esto puede corroborarse en el intercambio de palabras que no consideramos apropiados, tales como "metafísica" en vez de "ciencia divina", "teología" o "filosofía primera."

2 Cfr. Tomás de Aquino: Exposición del De Trinitate..., p.23: "La finalidad primordial de santo Tomás: clarificar el estatuto científico de la teología y el problema de la abstracción.”. Ahora bien, el presente trabajo no se enmarca en la enmarañada cuestión de los diferentes sentidos que pudiera tener la noción abstractio en Tomás de Aquino. Tampoco busca mostrar que el eje de interpretación respecto de la división de las ciencias tomísticas sea el caso de la abstractio, ya que esta línea de investigación no coincide esencialmente con la perspectiva de análisis aquí escogida, aunque ciertamente es paralela. Véase para ello la nota $\mathrm{n}^{\circ} 4$ y las conclusiones.

3 Jean-Pierre Torrell: Iniciación a Tomás de Aquino: su persona y su obra. Eunsa, Pamplona, 2002, p. 369: La obra De Trinitate fue redactada por Tomás de Aquino entre los años de su primera estancia parisina de 1257-1258 o a principios de 1259, entre la mitad del De Veritate y el principio de la Suma Contra Gentiles. 


\section{Mendoza, Simmons o Pasnau, ${ }^{4}$ las ciencias principalmente especulativas se dividen sobre la base de la abstracción, en los comentarios tomísticos de las obras aristotélicas ${ }^{5}$ dicha división tiene esencial asidero en la consideración del esse a través de cada uno de los subiecta de las ciencias. ${ }^{6}$ Por lo mismo, si dicha tesis fuese correcta, se acentuaría primero un cambio de perspectiva entre tales textos tomísticos, y seguidamente, la afirmación de una comprensión distinta del mismo Tomás respecto de las ciencias.}

4 Entre los problemas que conlleva la fusión de doctrinas de Tomás de Aquino y Cayetano parecería de no menor envergadura la utilización de la noción de abstractio como fundamento de la distinción y división de las ciencias. A ello se añade una segunda cuestión. Aquella que confunde en los mismos textos tomísticos la diferencia entre universales reales (pertinentes a las ciencias) y universales lógicos (pertinentes a la ciencia y arte de la lógica). Para esto último puede recurrirse críticamente al texto de, cfr. Juan Fernando SELLÉs: El hábito conceptual y la distinción entre los universales lógicos y reales según Tomás de Aquino. En: Diánoia. Vol. III, nº 61, 2008, pp. 47-71. Y de modo más general también puede verse el texto de, cfr. Gregorio CELADA LuEngO: El aprecio de santo Tomás por la sagrada doctrina como ciencia. En: Ciencia Tomista. Vol. 137, no 441, 2010, pp. 33-62: Dicho texto asume la diferencia real entre la doctrina tomística y el surgimiento del neotomismo moderno (el cual tiende a clasificar las ciencias desde la misma lógica). A continuación acentúa el hecho de que las ciencias tienen como fin ocuparse del esse y esencia de las cosas. Además, en torno al arraigo de la ciencia en la realidad por medio del esse expresado esencialmente por el juicio (científico), cfr. Cornelio Fabro: Participación y causalidad. Eunsa, Pamplona, 2009, pp. 142-160. Para el caso de la abstracción, cfr. Celina Ana Lertora Mendoza: Tomás de Aquino. Teoría de la ciencia. Ediciones del Rey, Buenos Aires, 1991, p. 8: "En cuanto a Santo Tomás generalmente se acepta que su teoría de la ciencia depende fundamentalmente de su concepción de los grados de abstracción de tal modo que los mismos textos del comentario a Boecio constituyen una teoría gnoseológica general y una teoría de la ciencia en particular. En esta postura se sitúan la mayoría de los tomistas antiguos y modernos." Existen numerosos estudios específicos sobre el tema de la abstracción que no he querido incluir por no ser la dirección ab initio escogida. Entre los autores que sostienen una interpretación tomista acompañada de la tradición escolástica moderna se puede traer a colación a, cfr. Edward. D. Simmons: In Defense of Total and Formal Abstraction. En: New Scholasticism. Vol. 29, 1955, pp. 427-440; cfr. Robert Pasnau: Abstract Truth in Thomas Aquinas. En: Henrik LagerLund: Representation and Objects of Thought in Medieval Philosophy, 2007, pp. 33-61; cfr. Cesáreo López Salgado: Abstractio y Separatio como acceso a la metafísica. En: Sapientia. Vol. XIX, n $\mathrm{n}^{\circ} 72,1964$, pp. 102-116; cfr. Gustavo Eloy Ponferrada: Nota Sobre Los grados de Abstracción. En: Sapientia. Vol. XXXIII, 1978, pp. 267-284. En cambio una introducción a la diferente interpretación entre Tomás de Aquino y Cayetano respecto de la noción de abstracción, cfr. Emiliano Javier Cuccia: Una controversia acerca del sentido de la abstracción. En: Silvana Filippi (ed.): Controversias Filosóficas, Científicas y Teológicas en el Pensamiento Tardo-Antiguo y Medieval. Paideia, Universidad Nacional de Rosario, Facultad de Humanidades y Artes, Rosario, 2011, p. 278: "La consideración que hace Tomás de Aquino de la abstracción posee una naturaleza íntimamente ontológica ya que la determinación de la abstracción se hace en razón de qué sea realmente conocido, si sustancia o accidente [...] En cambio la abstracción formal se encuentra inmersa en un ámbito lógico u objetivo, en el cual las distinciones en el ser del objeto se originan en el diverso modo de considerar una misma realidad conocida." Ahora bien, para el esclarecimiento de la doctrina tomística del esse en su originalidad trascendente, e irreductible al pensamiento lógico moderno y moderno escolástico (puesto que aquí anida la problemática relación entre abstractio y esse y la consiguiente división y clasificación de las ciencias), puede verse el clásico estudio de, cfr. Cornelio FaBro: Participación y causalidad..., pp. 19-80 (introducción), 251282 (interpretación neoescolástica).

5 Jean-Pierre Torrell: Iniciación a Tomás..., p. 365: El texto De Anima constituye el primer comentario tomístico de Aristóteles y fue redactado entre finales de 1267 y comienzos de 1268 . El último, en cambio, es el texto De Generatione, y fue escrito en 1272 o 1273 (p. 368). A su vez, para una distinción entre el pensamiento de Cayetano y el de Tomás, cfr. Ceferino Pablo Daniel MuÑoz: Concepto formal y concepto objetivo en Cayetano. Un análisis a partir de su comentario al De ente et essentia. En: Estudios Filosóficos. Vol. LXII, n 179, 2013, pp. 49-61.

6 Cfr. José María Felipe Mendoza: Cartografía epistémica concebida por Tomás de Aquino según su interpretación de las obras aristotélicas. En: Tópicos. № 39, 2010, pp.131-155. 
Según este contexto, las consideraciones siguientes se restringirán a un análisis clasificatorio de las ciencias según la littera tomística. En ello los textos citados atenderán principalmente a la definición de cada ciencia y sus vinculaciones.

\section{Presentación general del orden de las ciencias}

El prólogo de la tercera sección del comentario tomístico al De Trinitate de Severino Boecio se desenvuelve en dirección a un esclarecimiento más propicio de la tarea de la teología científica. ${ }^{7}$ Dos notas destacan en este sentido. Por un lado se menciona, en el comienzo del texto, la importancia del método como una cuestión que debe ser considerada previamente a la ciencia, cuando, citando a Aristóteles, dice: “[...] según la sentencia del filósofo, en el libro II de la Metafísica, [se afirma] que antes de [considerar] una ciencia hay que inquirir sobre el método de dicha ciencia [...]", y al final del mismo, la recurrente mención del método al decir: "[...] explica los métodos adecuados a cada una de las partes de esta ciencia [la parte especulativa]. In medias res, debe también señalarse que se atiende a las características propias de cada ciencia especulativa. Y así, cual corolario, este desenvolvimiento, mostrado mediante la estructura "método/características/método", parecería ser el adecuado para exponer qué y cuántas ciencias haya. Sin embargo, la c. 5ta principia con el art. $1^{\circ}$ que trata sobre la división de la ciencia especulativa y desplaza la importancia del método a la c. $6 \mathrm{ta},{ }^{10}$ anteponiéndose, de este modo, la necesidad de considerar, primero, cuáles sean los subiecta de las ciencias, y luego, investigar sobre sus métodos correspondientes. ${ }^{11}$

\footnotetext{
Quiere destacarse aquí el papel primordial de la razón en su incursión en los misterios de la teología trinitaria. Bajo este aspecto el texto De Trinitate de Tomás sigue la intención explícita de Boecio y se distancia sólo en parte de la propia de San Agustín, ya que este último también en su tratado De Trinitate investigó tales misterios con la razón. De este modo el comentario del de Aquino se abre paso principalmente a través de las tres doctrinas de Aristóteles (la intensa influencia de la filosofía aristotélica es claramente visible en el texto tanto de Boecio como de Tomás de Aquino), Boecio y Agustín de Hipona.

8 Tomás de Aquino: Sup. De Trin., pars 3, pr. 1: "Et quia secundum sententiam philosophi [...]."

9 Tomás de Aquino: Sup. De Trin., pars 3 pr. 6: "Deinde cum dicit: in naturalibus igitur etc., [...]."

10 Tomás de Aquino: Sup. De Trin., pars 3, q. 5, pr.: "Hic est duplex quaestio. Prima de divisione speculativae, quam in littera ponit. Secunda de modis, quos partibus speculativae attribuit."

11 Sobre la importancia de los métodos de las ciencias, cfr. Leo ElDERs: Sobre el método en santo Tomás de Aquino. En: Sociedad Tomista Argentina, Buenos Aires, 1992.
} 
Asimismo, si bien el texto tomístico considera con mayor detenimiento las ciencias especulativas que las propias prácticas o las artes, no quita ello que Tomás señale la finalidad de todo saber filosófico. Pues afirma: “[...] aun cuando en esto se divida la totalidad de la filosofía y de las artes, la división de la filosofía se hace respecto del fin [último que es] la felicidad (beatitudo), al cual toda la vida humana se ordena". ${ }^{2}$ La fuerza de esta afirmación se vuelve patente y decisiva cuando se entiende que en Tomás de Aquino la presencia real de la beatitudo ${ }^{13}$ no sólo se posiciona como fin ulterior, sino también y principalmente, como cierto eje transversal a cada ciencia. Por lo tanto, es el mismo Aquinate quien pareciera insistir en que es el hombre concreto quien busca su felicidad entre las ciencias. De donde, cualesquiera sean las divisiones de la filosofía, lo primero que este fraile dominico asienta es que semper et absolute ella debe mirar el fin último del hombre. Según ello se torna también ineludible decir que las relaciones entre las ciencias se vuelven un itinerario interior y pedagógico del espíritu humano, y que la ciencia máxima y directriz será también aquella que alegre plenamente al hombre.

Ahora bien, bajo la regencia de la beatitudo, la división de la filosofía y de las artes se expresa concretamente en Tomás de Aquino por el fin particular de cada uno de estos saberes. El conocimiento filosófico, nos dice el Doctor Angélico, se divide en especulativo y práctico, mientras que las artes comportan una distinción similar. ${ }^{14}$ De esto modo, como se verá a lo largo del presente texto, se muestra aquí la existencia de un orden de fines. El primero de ellos, al cual todo le queda sujeto, es el fin final de la beatitudo. Le continúa la subordinación del fin de las ciencias especulativas, el fin de las ciencias prácticas y el fin de las artes. Y por último, en analogía con esta subordinación, el Aquinate menciona las ciencias y las artes concretas, las cuales están ordenadas o a las ciencias especulativas, o a las ciencias prácticas, o a las artes.

12 Tomás de Aquino: Sup. De Trin., pars 3, q. 5, a. 1, ad 4: "Hoc tamen interest, cum in hoc dividitur philosophia totalis et artes, quod in divisione philosophiae habetur respectus ad finem beatitudinis, ad quem tota humana vita ordinatur."

13 No parece que en el estudio de las ciencias, respecto del pensamiento tomístico, se haya tenido suficientemente en cuenta la influencia de este fin último llamado beatitudo. Suele vincularse la felicidad a las virtudes éticas en general y se descuida la integración tomística de este fin final con las virtudes intelectuales. Sin embargo en esta dirección se ha estudiado, por un lado, la scientia como perfección del intelecto humano y, por el otro, como perfección de la mens (término tomístico de raíz agustiniano que facilita la vinculación de la experiencia del alma con la teología). Para el caso de las virtudes intelectuales, cfr. Juan Fernando SELLÉs: Los hábitos intelectuales según Tomás de Aquino. Eunsa, Pamplona, 2008.

14 Véase nota $n^{\circ} 42$. 
Las ciencias especulativas se distinguen de las ciencias prácticas en lo siguiente: $1^{\circ}$ ) el fin de la ciencia especulativa es la verdad; ${ }^{15} 2^{\circ}$ ) las ciencias especulativas tienen por fin aquellas cosas que no pueden hacerse mediante nuestro obrar; ${ }^{16} 3^{\circ}$ ) las ciencias especulativas consideran lo especulable en cuanto especulable, y según ello, se expone su diferencia interna: ${ }^{17}$ "Así, por tanto, a lo especulable, que es objeto de la ciencia especulativa, le compete por sí la separación (separatio) de la materia y del movimiento, o su aplicación a aquella. Y por ello según el orden de remoción (remotionis) de la materia y del movimiento se distinguen las ciencias especulativas". ${ }^{18}$

En cambio las ciencias prácticas presentan la siguiente característica: el fin es aquellas cosas que el hombre puede hacer, ${ }^{19} \mathrm{o}$ bien, aquello que se ordena a la acción. ${ }^{20} \mathrm{~A}$ su vez dicho criterio práctico demarca su diferencia interior con respecto a las artes cuando Tomás escribe que "la ciencia moral, aunque tenga como causa la acción, no es sin embargo aquella acción el acto de la ciencia, sino más de la virtud". ${ }^{21}$ Por ello la ética es para este dominico no tanto una reflexión y una doctrina sobre qué y cómo corresponde actuar, sino también y principalmente la vivencia de la misma virtud.

Ahora bien, sobre la base de las previas distinciones, el Aquinate se aplica al estudio de las ciencias concretas especulativas, porque las mismas son anteriores tanto a las ciencias prácticas como a las artes, ya que antes de actuar conviene saber, y el saber se dirige esencialmente a comprehender la naturaleza. Según este razonamiento, y en concordancia con lo expuesto anticipadamente sobre el criterio interno de distinción entre las ciencias especulativas, Tomás advierte que tales ciencias son exclusivamente tres, porque al fijar la dirección del intelecto a la naturaleza, se entiende a la vez que la naturaleza se dice principalmente esse como actus essendi de cada ente

\footnotetext{
15 Tomás de Aquino: Sup. De Trin., pars 3, q. 5, a. 1, co. 1: "Et ideo dicit philosophus in III de anima quod differunt ad invicem fine, et in II metaphysicae dicitur quod finis speculativae est veritas [...]."

16 Tomás de Aquino: Sup. De Trin., pars 3, q. 5, a. 1, co. 1: "Speculativarum vero scientiarum materiam oportet esse res quae a nostro opere non fiunt; unde earum consideratio in operationem ordinari non potest sicut in finem."

17 Tomás de Aquino: Sup. De Trin., pars 3, q. 5, a. 1, co. 2: "Et ideo oportet scientias speculativas dividi per differentias speculabilium, in quantum speculabilia sunt.”

18 Tomás de Aquino: Sup. De Trin., pars 3, q. 5, a. 1, co. 2.

19 Tomás de Aquino: Sup. De Trin., pars 3, q. 5, a. 1, co. 1: “Cum ergo oporteat materiam fini esse proportionatam, oportet practicarum scientiarum materiam esse res illas quae a nostro opere fieri possunt, ut sic earum cognitio in operationem quasi in finem ordinari possit."

20 Tomás de Aquino: Sup. De Trin., pars 3, q. 5, a. 1, ad 4: "[...] practicum vero, quod ordinatur ad operationem."

21 Tomás de Aquino: Sup. De Trin., pars 3, q. 5, a. 1, ad 3: "Scientia vero moralis, quamvis sit propter operationem, tamen illa operatio non est actus scientiae, sed magis virtutis, ut patet in libro Ethicorum."
} 
particular ${ }^{22}$ y que ellos son cognoscibles. Esto es, no sólo en virtud del esse se distinguen per se las ciencias especulativas, sino también y por lo mismo, no puede haber más distinciones internas que las ciencias mostradas por Tomás. De ahí que este criterio del esse, fijado como demarcación por el Doctor Angélico, es también sujeto primero sobre el cual, luego, el intelecto encontrará las diferencias entre las ciencias.

Respecto de la imposibilidad de la existencia de una cuarta ciencia especulativa se dice: "Sin embargo no es posible que haya algunas [otras] cosas que dependan de la materia según el intelecto y no según el esse, porque el intelecto en sí mismo es inmaterial. Y por ello, no existe un cuarto género de filosofía además de los anteriormente mencionados". ${ }^{23}$

Esto es, si el intelecto es inmaterial y el esse guarda relación con la materia, entonces esa relación es doble: o bien el esse se da a través de la materia, o bien, el esse no se aplica a la materia. Luego, el estudio del esse mediante la materia será un tipo de ciencia, y el estudio del esse sin materia será el de otra ciencia. Vale decir nuevamente: las posibilidades de otras ciencias especulativas dependen de la relación del esse con la materia, y la inteligencia conoce ese esse, ya material, ya inmaterial, porque en ambos casos se conoce el esse, el cual si fuese idéntico a la materia no podría decirse de él que pueda ser sin materia. Por lo tanto, es más propio del esse ser sin materia que con materia. De aquí se deduce que las dos ciencias naturales serán la física, para el primer caso, y la teología, para el segundo. Mas el texto alude a la existencia de una división tripartita. Y en esto Tomás añade que dicha tercera ciencia aparece mediante el estudio de la primera, llamada al presente ciencia física. Pero antes de adentrarse en las implicancias de este planteo, conviene al momento destacar que estas tres ciencias son la física, la matemática y la teología o ciencia divina ${ }^{24}$ para, desde aquí, señalar el orden entre tales saberes concretos. El criterio tomístico es el siguiente:

[...] debe decirse que aunque la ciencia divina sea por naturaleza la primera de todas las ciencias, sin embargo quoad nos hay otras anteriores. Y en efecto,

\footnotetext{
22 En este punto se abre el ámbito de los estudios de la creación en Tomás de Aquino. A modo de ejemplo pueden considerarse las siguientes obras: Cornelio Fabro: Participación y causalidad...; cfr. Ángel Luis GonzÁLEz: Ser y Participación, Estudio sobre la cuarta vía en Tomás de Aquino. Eunsa, Pamplona, 2001; cfr. Javier Pérez Guerrero: La creación como asimilación a Dios. Eunsa, Pamplona, 1996; cfr. Rudi Te Velde: Participation and Substantiality in Thomas Aquinas. E. J. Brill, New York, 1995.

23 Tomás de Aquino: Sup. De Trin., pars 3, q. 5, a. 1, co. 3.

${ }^{24}$ Tomás de Aquino: Sup. De Trin., pars 3, pr. 3: "Nam cum tres sint partes speculativae [...] autem tres partes praedictae: physica sive naturalis, mathematica, divina sive theologia."
} 
como dice Avicena [...] el orden de esta ciencia es como añadida después de las ciencias naturales [...] Y también de modo similar las matemáticas. En efecto, esta ciencia necesita para el conocimiento de las substancias separadas el conocimiento del número y el orden de los orbes celestes, que no es posible sin la astronomía, para lo cual se necesita de la matemática. ${ }^{25}$

Se reconoce aquí un doble criterio. Por un lado, aquel que muestra un orden de las ciencias naturaliter y por el otro, quoad nos. En torno al segundo, aparece en primer lugar la ciencia física, le continúa la matemática y se finaliza con la ciencia divina. ${ }^{26}$ En cambio, según el primero, solo se afirma que la ciencia divina es ciencia primera per se, para que luego aparezcan las dos restantes ciencias, sin que ello signifique un desvelamiento necesario respecto de cuál de ambas sigue a aquel saber de Dios. A su vez, de este doble criterio Tomás atiende tanto al enunciado quoad nos cuanto a la relación (virtuosa) que se desprende de la consideración de ambos criterios.

En el caso del criterio quoad nos pareciera que el orden no fuese sumamente claro. Por un lado Tomás ya ha dicho que la ciencia natural o física ha de aprehenderse primero, pero ahora escribe que "corresponde aprender la ciencia natural después de la matemática, porque las tesis universales de aquella necesitan experimentación y tiempo, aunque al ser cosas sensibles son naturalmente más evidentes que las cosas matemáticas, abstractas de la materia sensible". ${ }^{27}$ Esto es, el hecho de que "el principio del conocimiento natural es la percepción sensible de las creaturas" 28 parecería con todo un conocimiento anterior a la ciencia matemática, aunque fenoménico y débil, pues el hombre no estudiaría en esta ciencia sino sus rudimentos y ello de modo pedagógico. De ahí que, aunque sean más evidentes tales entes sensibles, sean también más inciertos en comparación con la certeza de la ciencia matemática. Por lo tanto, puede deducirse de aquí, aunque temerosamente, que para Tomás de Aquino, en el orden de las ciencias quoad nos, aparece primero la ciencia física, luego la matemática y finalmente la teología.

25 Tomás de Aquino: Sup. De Trin., pars 3, q. 5, a. 1, ad 9.

${ }^{26}$ Cfr. Tomás de Aquino: Sup. De Trin., pars 3, q. 5, a. 1, ad 9: "Et inde est quod Boethius ultimo ponit scientiam divinam, quia est ultima quoad nos."

27 Tomás de Aquino: Sup. De Trin., pars 3, q. 5, a. 1, ad 10: “[...] quod quamvis naturalis post mathematicam addiscenda occurrat, ex eo quod universalia ipsius documenta indigent experimento et tempore, tamen res naturales, cum sint sensibiles, sunt naturaliter magis notae quam res mathematicae a sensibili materia abstractae."

28 Tomás de Aquino: Sup. De Trin., pr. 1: "Sicut ergo naturalis cognitionis principium est creaturae notitia a sensu acepta $[\ldots]$." 
Ahora bien, en atención a la relación entre ambos criterios Tomás escribe las dos siguientes reflexiones:

$\mathrm{Ni}$ tampoco conviene que sea un círculo [vicioso] el hecho de que esta [ciencia] suponga [los principios] de aquella en la cual son utilizados, por el hecho de que una demuestra los principios de la otra, porque los principios que considera la ciencia natural de la filosofía primera no se demuestran en aquellas cosas que también el filósofo primero toma de la ciencia natural, sino que aquellos [los de la ciencia natural] son demostrados por otros principios que son en sí evidentes [los de la filosofía primera]. Y de modo similar el filósofo primero no demuestra los principios de la ciencia natural por medio de los principios que toma de esta [ciencia natural], sino [que estos principios son demostrados] por los principios en sí evidentes. Y por ellos no existe un círculo vicioso en la definición. ${ }^{29}$

Además, los efectos sensibles, por medio de los cuales proceden las demostraciones naturales, son más evidentes para nosotros en un comienzo, pero cuando por medio de ellos alcanzamos un conocimiento de las causas primeras, aparecerá por estas y para nosotros el porqué (propter quid) de aquellos efectos desde los cuales se prueban [luego] las demostraciones quia. Y así también la ciencia natural trata algunas cosas de la ciencia divina y no obstante por ella [la ciencia divina] se conocen los principios de aquella [la ciencia física]. ${ }^{30}$

\section{División ad intra de las ciencias especulativas}

El apartado precedente concluyó en la mostración de la relación armónica entre las ciencias física, matemática y teológica. Ahora conviene atender a los nombres de cada una de estas ciencias, sus definiciones y sus posibles divisiones. En el caso de la ciencia física, llamada también filosofía de la naturaleza, la definición es la siguiente:

Hay ciertos especulables que dependen de la materia según el esse, porque no pueden ser sino en la materia. Y estos se distinguen en cuanto dependen de la materia según el esse y del intelecto, como estos en los cuales en la definición

\footnotetext{
29 Tomás de Aquino: Sup. De Trin., pars 3, q. 5, a. 1, ad 9.

${ }^{30}$ Tomás de Aquino: Sup. De Trin., pars 3 q. 5 a. 1 ad 9.
} 
se coloca la materia sensible. De allí que sin la materia sensible no puedan inteligirse, ya que en la definición de hombre conviene considerar la carne y los huesos. Y de estas cosas es la física o filosofía natural. ${ }^{31}$

La exigencia de la presencia del esse en la materia conforma la substancia sensible, fin y subiectum de la ciencia física. Pues ella es el compuesto o todo íntegro en el que radica su principio de inteligibilidad que no es sino su forma sustancial o razón. ${ }^{32}$ Ahora bien, Tomás asienta sobre la base de dicha forma sustancial la posibilidad de la ciencia en tanto que considera dicha forma como inmóvil. Pues "las formas y las razones de las cosas, incluso de los existentes móviles, en cuanto se consideran en sí mismas se hallan ausentes de movimiento. Y así de ellas hay ciencias y definiciones". ${ }^{33}$ Ahora bien, el modo del intelecto de considerar dicha forma de la sustancia móvil como inmóvil es para Tomás de Aquino la siguiente:

De donde conviene que las formas (razones) consideradas de este modo, sobre las cuales puede haber ciencia, se consideren ausentes de materia signada y ausentes de todas las cosas que se siguen de la materia signada, no sin embargo de la materia no signada, porque de estas razones (nociones) depende la noción de forma que determina para sí la materia. Y por ello la forma (razón) de hombre, que significa la definición y de la cual también procede la ciencia, se considera también sin esta carne y sin estos huesos, pero no sin carne y sin huesos en modo absoluto. $\mathrm{Y}$ así las cosas singulares incluyen en su forma (razón) la materia signada, [y] los universales, en cambio, la materia común, como se dice en el VII [libro] de la metafísica, y por esto la anterior abstracción no se dice de la forma respecto de la materia en modo absoluto, sino del universal respecto del singular. ${ }^{34}$

De este pasaje no debe comprenderse que el fundamento de la ciencia física sea el ente móvil per se como fruto de una previa abstracción intelectual. Esto es, la operación de la abstracción no se convierte en la base previa que fundamenta la física, que es el ente móvil. No es la abstracción mental la

\footnotetext{
31 Tomás de Aquino: Sup. De Trin., pars 3, q. 5, a. 1, co. 3.

32 Tomás de Aquino: Sup. De Trin., pars 3, q. 5, a. 2, co. 1: "Ut autem probatur in VII metaphysicae, cum in substantia sensibili inveniatur et ipsum integrum, id est compositum, et ratio, id est forma eius [...]”.

33 Tomás de Aquino: Sup. De Trin., pars 3, q. 5, a. 2, co. 1: "Et ideo formae et rationes rerum quamvis in motu exsistentium, prout in se considerantur, absque motu sunt. Et sic de eis sunt scientiae et diffinitiones [...]".

34 Tomás de Aquino: Sup. De Trin., pars 3, q. 5, a. 2, co. 2.
} 
operación que coloca el fundamento extramental de la ciencia física. Por el contrario, la abstracción es una explicación posterior al previo hecho de la existencia de la sustancia sensible que de facto es conocida y de la cual hay efectivamente ciencia. Esto es, la abstracción justifica (en cuanto es posterior y de hecho explica) racionalmente el modo por el cual el hombre conoce la sustancia sensible. No es primero la abstracción y después el conocimiento de algo, sino primero el hecho de que positivamente existe una sustancia sensible y que naturalmente la conocemos, y luego la pregunta por el modo. Es decir, en Tomás de Aquino no se antepone el cómo al qué, sino que ante la evidencia de que conocemos algo, ${ }^{35}$ (v.g. esta sustancia sensible concreta: algún tipo de acacia) se procede luego a inquirir dos cuestiones: por un lado, cómo conocemos, y con ello el planteo se direcciona hacia una perspectiva gnoseológica; y por el otro, se interroga por sus causas, siendo este último camino el propio de la ciencia física per $s e .^{36}$

Ahora bien, debe señalarse que en la explicación tomística de la obtención de la forma inmóvil proveniente de la sustancia sensible móvil interesa esencialmente su finalidad. Huelga nuevamente decir que analíticamente se presentan tres pasos: $1^{\circ}$ ) la existencia de las sustancias sensibles y del hombre; $2^{\circ}$ ) el conocimiento humano de tales sustancias; $3^{\circ}$ ) la explicación modal del conocimiento. Esto es, la abstracción se halla sujeta entre el hombre y la naturaleza como una explicación tomística sobre el modo de conocimiento. Y por lo mismo, esta teoría de la abstracción puede ser estudiada al margen, aunque ella sea esencial, de la finalidad de las ciencias y su método concreto de proceder. El fin de la ciencia es la profundización inquisitiva de su subiectum, y ello se logra por medio de un estudio de la causalidad.

En el caso concreto de la filosofía de la naturaleza esa forma sustancial presente en el intelecto es el principio plenificativo de la ciencia física por su semejanza con la forma sustancial conformadora del compuesto sensible. ${ }^{37}$ Vale decir, al ser el fundamento de la física la existencia de los entes móviles, entonces aquello que el intelecto hace es captar dicha forma en su consideración de inmóvil y explayarse desde ella, por ella y a través

35 Tomás de Aquino: Sup. De Trin., pars 3, q. 5, a. 2, ad 2: “[...] quod forma intelligibilis est quiditas rei. Obiectum enim intellectus est quid, ut dicitur in III de anima. Quiditas autem compositi universalis, ut hominis aut animalis, includit in se materiam universalem, non autem particularem, ut dicitur in VII metaphysicae".

36 Tomás de Aquino: Sup. De Trin., pars 3, q. 5, a. 2, ad 4: "Ratione enim universali utitur sciens et ut re scita et ut medio sciendi. Per universalem enim hominis rationem possum iudicare de hoc vel de illo".

37 Tomás de Aquino: Sup. De Trin., pars 3, q. 5, a. 2, ad 5: “[...] quod quamvis universale non moveatur, est tamen ratio rei mobilis". 
de ella; $;^{38}$ y su explanación no es sino el hecho de que el intelecto explica racionalmente qué sea esa sustancia móvil y cuáles sean sus causas, lo cual será, posteriormente para Tomás, el contenido de su comentario al tratado de la física aristotélica.

Ahora bien, las sustancias sensibles son sumamente variadas. Ante ello Tomás de Aquino establece el siguiente criterio de distinción: "[...] una ciencia está contenida dentro de otra de doble modo. De uno como parte suya, porque su subiectum es parte del subiectum de aquella, como las plantas son cierta parte de los cuerpos naturales. De donde también la ciencia de las plantas está contenida bajo la ciencia natural como parte suya". ${ }^{39}$

Según el presente extracto, el subiectum de una ciencia particular debe formar parte del subiectum de una ciencia general. Luego, si la ciencia genérica se denomina física y en ella se consideran los cuerpos naturales, entonces todo lo que tenga cuerpo natural le quedará subordinado. Este es el caso de la botánica, según el expreso ejemplo del texto anterior, aunque podrían también añadirse entre los seres vivientes, y bajo el mismo criterio, las ciencias de la zoología ${ }^{40}$ y del hombre. Vale decir, por un lado a la física le queda sujeta como parte suya la biología en general, y por el otro, en tanto también el criterio es el propio del cuerpo natural, la geología y la astronomía. ${ }^{41}$

A la previa consideración Tomás añade otro modo de subordinación respecto de la ciencia física, cuando explica el caso de las ciencias/artes, al decir que algunas de ellas le quedan sujetas, no por su subiectum, sino en cuanto aquella asigna la causa esencial (propter quid) de las cosas de las que trata la ciencia inferior. Pero ello sólo en el caso de que esta última ciencia no busque demostrar aquellas causas, sino aceptarlas y valerse de las mismas para proceder en otras investigaciones y aplicaciones. El texto tomístico dice lo siguiente:

\footnotetext{
38 Tomás de Aquino: Sup. De Trin., pars 3, q. 5, a. 2, co. 3: "Alio modo secundum quod comparantur ad res, quarum sunt rationes; quae quidem res sunt in materia et motu. Et sic sunt principia cognoscendi illa, quia omnis res cognoscitur per suam formam. Et ita [...]".

39 Tomás de Aquino: Sup. De Trin., pars 3, q. 5, a. 1, ad 5.

${ }^{40}$ Cfr. Tomás de Aquino: Sup. De Trin., pars 2, q. 4, a. 2, co. 4: "Et ex hoc materiali sumitur genus, differentiae vero ex perfectione et imperfectione praedicta. Sicut ex hoc communi materiali, quod est habere vitam, sumitur hoc genus animatum corpus; ex perfectione $[\ldots]$ ".

${ }^{41}$ En esta dirección puede consultarse el excelente estudio de, cfr. Leo ElDERs: La filosofia della natura di San Tommaso D'Aquino. Filosofia della natura in generale, Cosmologia, Filosofia della natura organica, Antropologia filosófica. Librería Editrice Vaticana, Cittá del Vaticano, 1996.
} 
De otro modo una ciencia se contiene bajo otra como su subalterna cuando, a saber, la ciencia superior asigna la causa propter quid de aquellas, de las cuales [causas] se conocen en la ciencia inferior solo como causas quia, y así, por ejemplo, la música se coloca bajo la aritmética. Por lo tanto la medicina no se coloca bajo la física como una parte suya. En efecto, el subiectum de la medicina no es parte del subiectum de la ciencia natural según aquella razón (ratio) que es subiectum de la medicina. Pero en la sanación se procede también por el arte, y el arte es instrumento de la naturaleza, porque desde algunas virtudes naturales la sanación se perfecciona con el auxilio del arte; y por ello es que la causa propter quid respecto de la operación del arte conviene se tome desde las propiedades de las cosas naturales. Y por ello la medicina se subalterna a la física, y por la misma razón (ratio) la alquimia y la ciencia de la agricultura y todas aquellas que son de este modo. Y de ello se sigue que la física en sí misma y según todas sus partes es especulativa, aunque algunas ciencias prácticas le estén subordinadas. ${ }^{42}$

Ahora bien, si en vez de fijar la atención en la ciencia física, se lo hace en la ciencia matemática, la definición ofrecida por Tomás será la siguiente: "Y en verdad hay ciertas cosas que aunque dependan de la materia según el esse, no sin embargo respecto del intelecto, porque en tales definiciones no se coloca la materia sensible, como el caso de la línea y el número. Y de estas cosas es la matemática". ${ }^{43}$

Ante la evidencia de que efectivamente el hombre puede numerar, trazar líneas o formar cuerpos geométricos con las mismas, adviene la pregunta por el cómo. A semejanza del caso de la ciencia física, en la matemática también primero se advierte y constata que el hombre es capaz de ejercerla cual ciencia, incluso si desconociera las explicaciones gnoseológicas pertinentes. Por ello cuando Tomás se pregunta cómo es esto posible, introduce cabalmente su reflexión sobre la noción de abstracción. Con todo, dichas explicaciones delimitan las distinciones entre las ciencias física y matemática desde una perspectiva gnoseológica, pero en ningún caso explican in re el ejercicio de dichas ciencias, ni el orden científico de las mismas. Esto es, todo matemático entiende que la actividad matemática se soporta en la consideración de las sustancias como cantidades y unidades, y en cambio, la conciencia del conocimiento por medio del cual la mente abstrae de la sustancia sensible

\footnotetext{
42 Tomás de Aquino: Sup. De Trin., pars 3, q. 5, a. 1, ad 5.

43 Tomás de Aquino: Sup. De Trin., pars 3, q. 5, a. 1, co. 3.
} 
la forma cantidad no le es requerida esencialmente para su profesión. De hecho, la división interna de la matemática pura como aritmética y geometría solo es posible por la consideración intelectual de la cantidad de la sustancia, subiectum de dicha ciencia.

Para el Aquinate el fundamento in re de la matemática es el mismo ente sensible de la ciencia física, según que hay ciertas cosas que dependen de la materia según el esse. Pero en este fundamento, tal ciencia matemática no se dirige a la esencia del mismo ente sensible, sino a la categoría accidental de cantidad. Y esto es posible porque la inteligencia puede distinguir entre el subiectum de la ciencia física y la esencia del accidente cantidad. Esta distinción tomística tiene un fundamento categorial posibilitante: en la analítica de las categorías de la sustancia sensible se halla que algunos accidentes no dependen en su esencia de la materia esencial de dichas sustancias. Esto es, la esencia de la matemática, para Tomás de Aquino, no depende de la esencia de las sustancias sensibles, sino de la esencia del accidente de cantidad. Mas, respecto de la esencia de dicho accidente, la matemática radica en lo que haya de inteligible en ella. Por lo tanto, la inteligibilidad del accidente de cantidad es el principio plenificante del fundamento de la ciencia matemática, y por este fundamento luego dicha ciencia estudiará las líneas, los números y las figuras. Conviene insistir: para el desarrollo de dicha disciplina basta considerar la sustancia sensible como cantidad. Y por medio de ello se explicará la unidad cuantitativa mínima (el número uno), y la consiguiente enumeración de los entes sensibles, (v.g. las operaciones aritméticas), y a su vez, la ciencia geométrica, porque lo medible solo es tal sobre la base de la cantidad.

A su vez a esta previa distinción tomística, operada en el interior de la ciencia matemática, Tomás la explica y la expande hacia la ciencia física del siguiente modo:

Así pues los principios de la matemática son aplicables a las cosas naturales, pero no al revés, ya que la física supone la matemática, pero no al contrario [...] Y por ello, acerca de las cosas físicas y matemáticas se descubren tres órdenes de ciencias. Algunas, ciertamente, son puramente naturales, las cuales consideran las propiedades de las cosas naturales en cuanto son de este modo, como la física, la agricultura y demás cosas parecidas. Otras, en verdad, son puramente matemáticas, las cuales tratan sobre las cantidades de modo absoluto, como la geometría sobre la magnitud, y la aritmética sobre el número. 
Y otras son [ciencias] medias, las cuales aplican los principios matemáticos a las cosas naturales, como la música, la astrología y cosas de este modo. ${ }^{44}$

El Aquinatense distingue tres órdenes de ciencias según un criterio fáctico. Uno de los grupos, por ocuparse de las sustancias naturales y sus propiedades, recibe el nombre de ciencia física en general. Esto es, entre las propiedades de las cosas naturales unas se refieren a las bióticas y otras a las abióticas. Siendo ambas subordinadas a la ciencia física, entre las primeras Tomás menciona la agricultura, y entre las segundas, plausiblemente el nombre de física se refiera a los minerales, elementos o fenómenos similares. A su vez este compendio de saber propio del naturalista, porque es quien entiende de seres naturales, es, en comparación con la matemática, el primero. A continuación se describe la ciencia matemática pura, porque sin una comprensión de la aritmética y la geometría no podrían luego estudiarse los astros (propiamente ciencia media), ni la música (entre ciencia y arte).

Las ciencias medias deben colocarse entre las distinciones internas de la matemática y no de la ciencia física, ya que ellas "son más afines a la matemática, porque en su consideración lo que es físico es cuasi material, y en cambio lo que es matemático es cuasi formal [...]". "Y "Y por eso las ciencias medias demuestran sus conclusiones acerca de las cosas naturales con medios matemáticos". ${ }^{46}$

Luego de la consideración ad intra de las ciencias especulativas de la física y la matemática, resta considerar quoad nos la última de ellas: la ciencia teológica. Tomás, en la definición del término teología, ${ }^{47}$ ofrece una síntesis de sus nombres y razones:

$\mathrm{Y}$ verdaderamente hay especulables que no dependen de la materia según el esse, porque pueden ser sin la materia o nunca ser en la materia, como Dios y el ángel, o a veces en la materia y a veces no, como la substancia, la cualidad, el ente, la potencia, el acto, lo uno y lo mucho y cosas de este modo.

\footnotetext{
44 Tomás de Aquino: Sup. De Trin., pars 3, q. 5, a. 3, ad 6.

45 Tomás de Aquino: Sup. De Trin., pars 3, q. 5, a. 3, ad 6: "Quae tamen magis sunt affines mathematicis, quia in earum consideratione id quod est physicum est quasi materiale, quod autem est mathematicum est quasi formale".

46 Tomás de Aquino: Sup. De Trin., pars 3, q. 5, a. 3, ad 6: "Et propter hoc demonstrant conclusiones suas circa res naturales, sed per media mathematica".

47 Aquí se presenta solo un resumen de lo que en otro momento fue un seguimiento detallado de los nombres de la teología como ciencia. Cfr. José María Felipe Mendoza: Aproximación a una misma ciencia de tres nombres: Methaphysica, Philosophia Prima y Theologia en el comentario de Tomás de Aquino al De Trinitate boeciano. En: Estudios Filosóficos. Vol. LXII, n 179, 2013, pp. 99-114.
} 
De todas ellas es la teología, es decir, la ciencia divina, porque lo propio del conocimiento en aquellas cosas es Dios, lo cual de otro modo se dice metafísica, esto es, trans-física, porque después de la física la aprehendemos, puesto que conviene alcanzar las cosas no sensibles desde las cosas sensibles. Y también se dice filosofía primera en cuanto todas las otras ciencias toman de ella sus principios y la siguen. ${ }^{48}$

El pasaje tomístico comienza en apariencia refiriéndose de modo directo a una división de ciencias según su relación con la materia. Antes de ello habla de ciertos especulables que no son sino por el esse, anunciado más adelante. A partir de tal esse se desprenden los especulables de los cuales trata la ciencia. Y así, el esse, raíz de la ciencia, se manifiesta a través de aquellos especulables que se precisan según ciertas divisiones. En efecto, la ciencia no trata sobre los especulables per se, sino porque ellos dependen radicalmente del esse que los constituye como existentes.

Esos especulables, no producidos por el hombre, sino contemplados por él, pueden ser, de acuerdo con el Aquinate, de dos modos: según se den en la materia con o sin necesidad lógico-metafísica. Ahora bien, si se dan en la materia, cabe una posibilidad, y esa es la ciencia física, pues la aplicación de estas nociones en la materia configura dicha ciencia. A su vez las mismas nociones de "sustancia, cualidad, ente, potencia, acto, uno y muchos" pueden darse sin materia, y con ello aparece la alternativa de la ciencia que recibe el nombre de metafísica.

Ahora bien, el estudio de tales términos sin materia es llamado por Tomás primeramente "teología" antes que con alguno de sus otros nombres. Por medio de esta mención quiere señalarse que en dicha ciencia ${ }^{49}$ el subiectum propio es Dios, "porque lo propio del conocimiento en aquellas cosas es Dios". Sin embargo el texto añade otra denominación para la teología. A renglón seguido enuncia la misma ciencia como "metafísica" y explica su sentido en relación con el conocimiento humano y no con el subiectum teológico al decir: "esto es, trans-física, porque después de la física la aprehendemos, puesto que conviene alcanzar las cosas no sensibles desde las cosas sensibles”.

\footnotetext{
48 Tomás de Aquino: Sup. De Trin., pars 3, q. 5, a. 1, co. 3.

49 Tomás de Aquino: Sup. De Trin., pars 3, q. 5, a. 4, co. 1: "Responsio. Dicendum quod ad videntiam huius quaestionis scire oportet quae scientia divina scientia dici debeat".
} 
Y finalmente llama a la teología "filosofía primera" porque "todas las otras ciencias toman de ella sus principios y la siguen". ${ }^{50}$

Con todo, debe advertirse que el salto cualitativo de la metafísica a la teología por la introducción de la fe, como elemento esencial para comprender qué sea cada cosa en tanto que en ellas Dios también se muestra, no supone que los nombres señalen, al menos para Tomás de Aquino, dos ciencias diversas. ${ }^{51}$ Bajo las mismas características atribuidas a la teología de sine motu abstracta e inseparabilis ${ }^{52}$ ahora el Aquinate añade la fe, y por medio de ella, coinciden lo que las cosas son y la contemplación humana ${ }^{53}$ de aquel existir, uniéndose de este modo dos vertientes: por un lado, la naturaleza en sí misma, es decir, Dios y la creación, y por el otro, el hombre que comprende, como viator, esa naturaleza en su máxima intensividad. En este sentido Tomás hace la siguiente advertencia: "Por lo tanto, los que en la sagrada doctrina utilizan argumentos filosóficos poniéndolos al servicio de la fe no mezclan agua con vino sino que convierten el agua en vino". ${ }^{4}$

La teología, entonces, habiendo culminado por las Sagradas Escrituras en la iluminación otorgada por la fe, utiliza, sin repugnancia, argumentos filosóficos, es decir, razona ${ }^{55}$ desde aquellos principios propios de sus otros dos nombres, los cuales, junto con la fe, ${ }^{56}$ conducen al hombre a una comprensión más intensiva de la misma realidad. ${ }^{57}$

${ }^{50}$ Cfr. Tomás de Aquino: Sup. De Trin., pars 3, q. 6, a. 1, co. 22: "Tota autem consideratio rationis resolventis in omnibus scientiis ad considerationem divinae scientiae terminatur [...] Ultimus ergo terminus resolutionis in hac via est, cum pervenitur ad causas supremas maxime simplices, quae sunt substantiae separatae [...]."

51 Tomás de Aquino: Sup. De Trin., pars 3, q. 5, a. 4, co. 4: "Sic ergo theologia sive scientia divina est duplex. Una, in qua considerantur res divinae non tamquam subiectum scientiae, sed tamquam principia subiecti, et talis est theologia, quam philosophi prosequuntur, quae alio nomine metaphysica dicitur [...]".

52 Tomás de Aquino: Sup. De Trin., pars 3, pr. 5: "Deinde ostendit de quibus sit tertia, scilicet divina: theologia, id est tertia pars speculativae, quae dicitur divina vel metaphysica vel philosophia prima, est sine motu, in quo convenit cum mathematica et differt a naturali, abstracta, scilicet a materia, [...]".

53 Tomás de Aquino: Sup. De Trin., pars 3, q. 6, a. 1, ad 24: "Ad quartum dicendum quod cognitio etiam fidei maxime pertinet ad intellectum. Non enim ea rationis investigatione accipimus, sed simplici acceptione intellectus tenemus. Dicimur autem ea non intelligere, in quantum intellectus eorum [...]".

54 Tomás de Aquino: Sup. De Trin., pars 1, q. 2, a. 3, ad 5.

55 Tomás de Aquino: Sup. De Trin., pars 3, q. 6, a. 1, ad 21: "Ad primum ergo dicendum quod intellectualiter procedere non attribuitur scientiae divinae, quasi ipsa non ratiocinetur procedendo de principiis ad conclusiones, sed quia eius ratiocinatio est intellectuali considerationi propinquissima et conclusiones eius principiis".

56 Tomás de Aquino: Sup. De Trin., pars 3, q. 5, a. 4, ad 3: "Ad tertium dicendum quod scientia divina, quae est per inspirationem divinam accepta, non est de Angelis sicut de subiecto, sed solum sicut de his, quae assumuntur ad manifestationem subiecti. Sic enim in sacra Scriptura agitur de Angelis [...]".

57 Tomás de Aquino: Sup. De Trin., pars 3, q. 5, a. 4, ad 8: "Ad octavum dicendum quod sicut fides, quae est quasi habitus principiorum theologiae, habet pro obiecto ipsam veritatem primam et tamen quaedam alia ad creaturas pertinentia in articulis fidei continentur, in quantum contingunt aliquo [...]”. 
En efecto, pareciera que los textos tomísticos señalasen el siguiente sendero: la profundización del ens llevaría consigo la revelación del esse, cuya evidencia progresaría gradualmente en una teofanía conducente a Dios como esse per se subsistens. Y de este modo la fe sería el elemento esencial que, como gracia no merecida, iluminaría los "artículos de fe", y presentaría ante el intelecto al ens y sus modos de ser bajo la denominación de "preámbulos de la fe". Vale decir: ellos no contradicen la naturaleza creada y colaboran en el hombre para inteligir a Dios con mayor perfección.

A su vez bajo este respecto pueden diferenciarse dos modos de hacer teología: ${ }^{58}$ aquella que surge desde la física y se eleva hacia la metafísica, llamada con propiedad teología filosófica, ${ }^{59}$ y aquella que desde la fe efluye hacia las substancias consideradas como creaturas. No obstante la primera está incompleta sin la segunda, y ésta no puede ser cabalmente explicada sin la primera.

Si a la metafísica y a la filosofía primera les compete estudiar los "preámbulos de la fe", en virtud de sus principios, a la teología le corresponden los "artículos de fe", los cuales, quasiprincipia, orientan la dialéctica de la razón con rectitud hacia los misterios de la fe. No se superponen de este modo los

58 Cfr. Pedro Javier Moya Obradors: El ser en Santo Tomás de Aquino según Étienne Gilson. En: Anales de filosofía. Vol. IV, 1986, p. 179: "Está claro que al comentar a Aristóteles, está de acuerdo con él [Tomás de Aquino], pero posteriormente da un paso adelante al percatarse de que esta homogenidad entre teología y metafísica obliga a escoger entre dos metafísicas: la que se refiere al ente en cuanto ente (ens commune), y la que se dirige a un ser particular, individual, cual es el ser divino. De aquí se explica el que Aristóteles no conociera más que una teología, la que forma parte de la metafísica; Santo Tomás conocía dos: la que forma parte de la metafísica y la que la trasciende, porque se funda en la palabra de Dios". Con todo, esta doble distinción de la metafísica proviene acertadamente de un análisis histórico, mientras que, si por otro lado, se considera, a raíz de ellas, cómo la metafísica, desarrollada por paganos, se vuelve cristiana, entonces se observaría especulativamente que si se cumple este paso se trataría de una metafísica que habilitaría la posibilidad de descubrir in ente el esse en cuanto Dios. El texto continúa: "Pero estas dos teologías no pueden contradecirse: es más, deben integrarse. Y las reflexiones de Aristóteles, iluminadas por los datos de la Revelación, aparecen mucho más claras y con una enorme potencialidad. Así, mientras Aristóteles habla de que lo que constituye la felicidad del hombre es la contemplación del objeto de especulación más perfecto, Tomás de Aquino va todavía más lejos y declara que la felicidad suprema del hombre es la visión de la misma esencia divina por toda la eternidad. Y aquí está la cuestión: las mismas fórmulas aristotélicas presentan una extraordinaria novedad en la obra del Aquinate: la filosofía primera misma se hace teología cuando se ordena al conocimiento de Dios; el ser divino es un fin, mientras que en el filósofo griego no dejaba de ser algo inalcanzable”. De aquí se concluyen tres cosas: En primer lugar el paso de la filosofía primera a la metafísica; luego, de esta última hacia la teología; y finalmente, de la distinción y complemento entre la teología filosófica, llamada también metafísica, y la teología cristiana. Así, la tesis de que haya dos teologías es verdadera cuanto a la historia, pero es falsa cuanto a la especulación. Pues en este caso la teología pagana queda integrada en la cristiana y en vez de comprender dos teologías debería decirse dos modos o caminos de una misma teología o, si se quiere, un mismo camino de dos etapas. En efecto, por la investigación racional de la mente cristiana se alcanza el ente y luego, a través suyo, el esse, para finalmente revelarse como Dios.

59 Véase el clásico estudio de, cfr. Leo Elders: The Philosophical Theology of St. Thomas Aquinas. E. J. Brill, New York, 1990. 
principios de una con los de la otra, pues el ens en los "preámbulos de la fe" es asumido por los "artículos de la fe" en una nueva dimensión comprensiva de la realidad como creación mistérica. ${ }^{60}$

Finalmente, si por un lado la ciencia teológica no presenta divisiones internas, por el otro, le quedan sujetas todas las ciencias y las artes, coronándose efectivamente como ciencia primera. Pues la metafísica o teología es una ciencia especial a la que todas las ciencias se hallan sujetas por considerar una cierta parte del ente, ${ }^{61}$ como el ente material o físico.

\section{Consideraciones finales}

La perspectiva tomística de la división de las ciencias según el texto De Trinitate fija una serie de consideraciones de particular interés para el tomismo contemporáneo: $1^{\circ}$ ) existe un fin último llamado beatitudo al cual quedan sujetas las tres esferas de las ciencias especulativas, las ciencias prácticas y las artes en general; $2^{\circ}$ ) el orden genérico descendente de las ciencias es el siguiente: ciencias especulativas, ciencias prácticas, artes en general; $3^{\circ}$ ) en la ciencia especulativa se convierten el esse y el verum, demarcando simultáneamente su límite ad intra y ad extra; $3.1^{\circ}$ ) la relación del esse con la materia es el criterio de división interna de las ciencias especulativas. Y ese criterio es doble: A) naturaliter, B) quoad nos: A.1) la ciencia divina es ciencia primera y las otras ciencias le están subordinadas, sin que Tomás indique explícitamente cuál sea ese orden; B.1) a. física; b. matemática; c. ciencia divina; $3.1 .1^{\circ}$ ) la relación

\footnotetext{
${ }^{60}$ Cfr. Tomás de Aquino: Sup. De Trin., pr. 1: "Philosophi enim, qui naturalis cognitionis ordinem sequuntur, praeordinant scientiam de creaturis scientiae divinae, scilicet naturalem metaphysicae. Sed apud theologos proceditur e converso, ut creatoris consideratio considerationem praeveniat creaturae." A partir de aquí se establece la íntima conexión entre los nombres "teología” y "sacra doctrina" por una parte y la creación como acto esencial de la Trinidad por la otra. Para ello, cfr. Gregorio Celada Luengo: El aprecio de santo Tomás...; cfr. Pablo Carlos Sicouly: Sacra doctrina en santo Tomás de Aquino. Una opción con implicancias para la comprensión de la teología y su relación con la filosofía y las ciencias. Interpretaciones y perspectivas. En: Studium, Filosofía y Teología. Vol. VIII, fasc. XVI, 2005, pp. 291-307; cfr. Santiago SANz: Fe y razón ante el misterio de la Trinidad creadora según santo Tomás. En: Scripta Theologica. Vol. 36, n 3, 2004, pp. 911-929; cfr. Leo Elders: El método en la sacra doctrina según santo Tomás de Aquino. En: Cristo y el Dios de los cristianos. Hacia una comprensión actual de la teología. XVIII Simposio Internacional de Teología de la Universidad de Navarra (1997). Ed. por José Morales et al, Universidad de Navarra, Pamplona, 1998, pp. 279-291.

61 Tomás de Aquino: Sup. De Trin., pars 3, q. 5, a. 1, ad 6: “[...] quamvis subiecta aliarum scientiarum sint partes entis, quod est subiectum metaphysicae, non tamen oportet quod aliae scientiae sint partes ipsius. Accipit enim unaquaeque scientiarum unam partem entis secundum $[\ldots]$ ".
} 
establecida por Tomás de Aquino entre A y B es armónica y virtuosa; $4^{\circ}$ ) las ciencias prácticas y las artes quedan siempre sujetas a las ciencias especulativas.

Entre las ciencias especulativas la teología no presenta divisiones internas con subiecta diferentes; solo nombres distintos, cuyo orden entre nombres, desde la comprensión humana que comienza en lo imperfecto y culmina en lo perfecto, es: a. "teología" como "filosofía primera"; b. "teología" como "metafísica"; c. "teología" como "teología". En cambio la ciencia física o filosofía natural, bajo el criterio físico que empieza en lo imperfecto y termina en lo perfecto, se divide en: a. sustancias abióticas, como los minerales, astros o elementos; b. sustancias bióticas: b.1. Ciencia botánica; b.2. Ciencia zoológica; b.3. Ciencia humana o antropología en general. Finalmente la ciencia matemática se divide en: a. geometría; b. aritmética; c. ciencias medias: astronomía y ciencias/artes cuando su principio teórico sea el número (v.g. la música).

Ahora bien, este sucinto esquema sobre la división tomística de las ciencias está enraizado en la dependencia del intelecto respecto del esse. Pues las ciencias miran al, y se despliegan del universal real (forma/ ratio de las sustancias concretas), y ello no es sino afirmar que se buscan las causas de las cosas. Así, en el caso de la ciencia física, la botánica por ejemplo, estudia árboles concretos, como los tipos de abetos, acacias, etc.

La razón de esta división está fundada en la regencia del esse como directriz del intelecto y está reflejada en las definiciones tomísticas de las ciencias, pues tales definiciones dan constancia del tipo de sustancia a considerar.

Contra esta comprensión aparece una clasificación lógico/gnoseológica difundida al parecer en numerosas obras del tomismo moderno y contemporáneo. Y en ello, si dicha clasificación se presenta como auténtica, se corre el riesgo de volver dependiente la realidad del modo cómo el hombre conoce. Por esto, ha de tenerse presente que para Tomás de Aquino: $1^{\circ}$ ) la clasificación de los saberes científicos no depende esencialmente de la gnoseología humana y/o del modo cómo lo conocido se hace presente y existe en la mente ${ }^{62}$ (posición especulativa próxima a, conducente a, o idéntica al representacionismo y ajena al pensamiento tomístico); $2^{\circ}$ ) el modo humano

${ }^{62}$ Un estudio clásico en esta dirección sobre el pensamiento de Tomás de Aquino puede verse en: José De ERCILLA: De la imagen a la idea. Estudio crítico del pensamiento tomista. Gredos, Madrid, 1959. En dirección al esclarecimiento de la verdad que se presenta ante el intelecto, cribando posiciones tomistas contemporáneas angloparlantes, tales como O’Callaham, Campbell, Conell, Dewan, etc., puede consultarse el texto de, cfr. Cruz GonzÁlez-Ayesta: La verdad como bien según Tomás de Aquino. Eunsa, Pamplona, 2006. 
de alcanzar el saber científico físico, matemático o teológico se manifiesta claramente como una cuestión diversa, aunque paralela, que debe ser estudiada en forma diferenciada (principalmente la noción de abstractio); $3^{\circ}$ ) el orden de las ciencias per se propuesto por Tomás deberá ser el mismo para los hombres, los ángeles y Dios; $4^{\circ}$ ) el ordenamiento quoad nos de las ciencias marca el distanciamiento entre el orden dado por los hombres, los ángeles y Dios; $5^{\circ}$ ) el orden per se de las ciencias manifiesta el ordenamiento absoluto de la naturaleza (ya que su correlato es la gradación óntica de la creación: minerales, plantas, animales, hombres y ángeles), y en consecuencia, coinciden esencialmente para la comprensión humana la causalidad trascendental del universo y el modo absoluto del conocimiento divino.

\section{Bibliografía}

Celada Luengo, Gregorio: El aprecio de santo Tomás por la sagrada doctrina como ciencia. En: Ciencia Tomista. Vol. 137, 2010, pp. 33-62.

Cornelio Fabro: Participación y causalidad. Eunsa, Pamplona, 2009.

CuCCIA, Emiliano Javier: Una controversia acerca del sentido de la abstracción. En: Silvana FILIPPI (ed.): Controversias Filosóficas, Científicas y Teológicas en el Pensamiento Tardo-Antiguo y Medieval. Paideia Publicaciones, Universidad Nacional de Rosario, Facultad de Humanidades y Artes, Rosario, 2011, pp. 273-281.

De Ercilla, José: De la imagen a la idea. Estudio crítico del pensamiento tomista. Gredos, Madrid, 1959.

ElDERs, Leo: El método en la sacra doctrina segín santo Tomás de Aquino. En: Cristo y el Dios de los cristianos. Hacia una comprensión actual de la teología. XVIII Simposio Internacional de Teología de la Universidad de Navarra, (1997). Ed. por José Morales et al, Universidad de Navarra, Pamplona, 1998, pp. 279-291.

Elders, Leo: La filosofia della natura di San Tommaso D'Aquino. Filosofia della natura in generale, Cosmologia, Filosofia della natura organica, Antropologia filosófica. Librería Editrice Vaticana, Cittá del Vaticano, 1996.

Elders, Leo: Sobre el método en santo Tomás de Aquino. Sociedad Tomista Argentina, Buenos Aires, 1992. 
Elders, Leo: The Philosophical Theology of St. Thomas Aquinas. E. J. Brill, New York, 1990.

GonzÁlez, Ángel Luis: Sery Participación, Estudio sobre la cuarta vía en Tomás de Aquino. Eunsa, Pamplona, 2001.

GonzÁlez-Ayesta, Cruz: La verdad como bien según Tomás de Aquino. Eunsa, Pamplona, 2006.

Lertora Mendoza, Celina Ana: Tomás de Aquino. Teoría de la ciencia. Ediciones del Rey, Buenos Aires, 1991.

Lopez Salgado, Cesáreo: Abstractio y Separatio como acceso a la metafísica. En: Sapientia. Vol. XIX, nº 72, 1964, pp. 102-116.

Mendoza, José María Felipe: Aproximación a una misma ciencia de tres nombres: Methaphysica, Philosophia Prima y Theologia en el comentario de Tomás de Aquino al De Trinitate boeciano. En: Estudios Filosóficos. Vol. LXII, nº 179, 2013, pp. 99-114.

Mendoza, José María Felipe: Cartografía epistémica concebida por Tomás de Aquino según su interpretación de las obras aristotélicas. En: Tópicos. $\mathrm{N}^{\circ}$ 39, 2010, pp.131-155.

Moya Obradors, Pedro Javier: El ser en Santo Tomás de Aquino según Étienne Gilson. En: Anales de filosofía. Vol. IV, 1986, pp. 175-186.

Muñoz, Ceferino Pablo Daniel: Concepto formaly concepto objetivo en Cayetano. Un análisis a partir de su comentario al De ente et essentia. En: Estudios Filosóficos. Vol. LXII, nº 179, 2013, pp. 49-61.

Pasnau, Robert: Abstract Truth in Thomas Aquinas. En: LagerLund, Henrik: Representation and Objects of Thought in Medieval Philosophy, 2007, pp. 33-61.

Pérez Guerrero, Javier: La creación como asimilación a Dios. Eunsa, Pamplona, 1996.

Ponferrada, Eloy Gustavo: Nota Sobre Los grados de Abstracción. En: Sapientia. Vol. XXXIII, 1978, pp. 267-284.

Sanz, Santiago: Fe y razón ante el misterio de la Trinidad creadora según santo Tomás. En: Scripta Theologica. Vol. 36, no 3, 2004, pp. 911-929.

SELLÉs, Juan Fernando: El hábito conceptual y la distinción entre los universales lógicosy reales según Tomás de Aquino. En: Diánoia. Vol. III, nº 61, 2008, pp. 47-71.

Sicouly, Pablo Carlos: Sacra doctrina en santo Tomás de Aquino. Una opción con implicancias para la comprensión de la teología y su relación con la filosofía y las ciencias. 
Interpretaciones y perspectivas. En: Studium, Filosofía y Teología. Vol. VIII, fasc. XVI, 2005, pp. 291-307.

Simmons, Edward D.: In Defense of Total and Formal Abstraction. En: New Scholasticism. Vol. 29, 1955, pp. 427-440.

TE Velde, Rudi: Participation and Substantiality in Thomas Aquinas. E. J. Brill, New York, 1995.

Tomás de Aquino: Exposición del De Trinitate de Boecio. Introducción, traducción y notas de A. García Marques y J. A. Fernandez, Eunsa, Pamplona, 1986.

Torrell, Jean - Pierre: Iniciación a Tomás de Aquino: su persona y su obra. Eunsa, Pamplona, 2002. 